\title{
Catalog Subject Searches in the Yale Medical Library
}

BY BENEDICT BROOKS AND FREDERICK G. KILGOUR

THE PURPOSE of the present study was to obtain specific data concerning the heaviest use of the subject cards in the catalog of the Yale medical library. These data will serve in the design of a catalog computerization project being carried out at the medical libraries of Columbia, Harvard, and Yale universities.

A search of the literature reveals some thirty surveys on the use of the card catalog, ${ }^{1}$ but most do not contain information useful to this investigation. Frarey ${ }^{2}$ provides an excellent review of the studies of card catalog use, one of his summary statements being that subject use of the catalog had been found to be about equal to author use. Jackson gives the results of the only attempt to obtain comprehensive information on a statistically meaningful scale. He shows "subject searches" as 43 per cent and "known-item searches" as 57 per cent for special libraries, the lowest percentage of "subject searches" for any of the library categories listed. The mean was 52 per cent "subject searches" and 48 per cent "known-item searches." Spalding, ${ }^{4}$ analyzing call slips at the Library of Congress, concludes that 25 to 50 per cent use is made of the subject approach. Emily Brown ${ }^{5}$ investigated the

\footnotetext{
${ }^{1}$ Sidney L. Jackson, Catalogue Use Study, edited by Vaclav Mostecky. (Chicago: ALA, Resources and Technical Services Division, Cataloging and Classification Section, Policy and Research Committee, 1958), p.51.

${ }^{2}$ Carlyle J. Frarey, "Studies of the Use of the Subject Catalog; Summary and Evaluation," in Maurice F. Tauber (ed.) The Subject Analysis of Library Materials (New York: School of Library Service, Columbia University, 1953), pp.147-66.

3 Jackson, op. cit., p.10.

4C. Sumner Spalding, "The Use of Catalog Entries at the Library of Congress," Journal of Cataloging and Classification, VI (Fall 1950), 95-100.

${ }^{5}$ Emily Klueter Brown, The Use of the Catalogue in a University Library, (Master's thesis, University
}

Mr. Brooks is a Cataloger and Mr. Kilgour is Librarian, Yale Medical Library.

use of the card catalog at the library of the University of Wisconsin. She reported that the subject division received 13 per cent of the use while the author-title division received 87 per cent and that staff use accounted for 28 per cent of the total. Although the majority of those using the subject catalog used only one subject heading, the largest number of subject headings searched was seven, while the average was 3.8 .

\section{Materials AND Methods}

A plot made of recorded circulation for the preceding year in the Yale medical library served as the basis for selecting a week of heavy use. Since this plot showed a fairly steady high of library use during October and November, the choice fell to Monday, October 28, through Friday, November 1, 1963, as the period of observation.

The card catalog of the Yale medical library consists of a single large case, containing in its two sides cards in a dictionary arrangement constituting a single alphabet. An observer on the opposite side of the room, facing the single free end, has no difficulty simultaneously noting activity at both sides. A continuous record made by an observer as catalog

of Chicago, Faculty of the Graduate Library School) $60 l$. Another pertinent study of a university library with generally similar results on card catalog use is Robert L. Bovey and Satinder Kumer Mullick, "A Study of Library Usage," in Johns Hopkins University Research Library, Progress Report on an Operations Research and Systems Engineering Study, (Baltimore: 1963) Section IV, pp.53-108. 


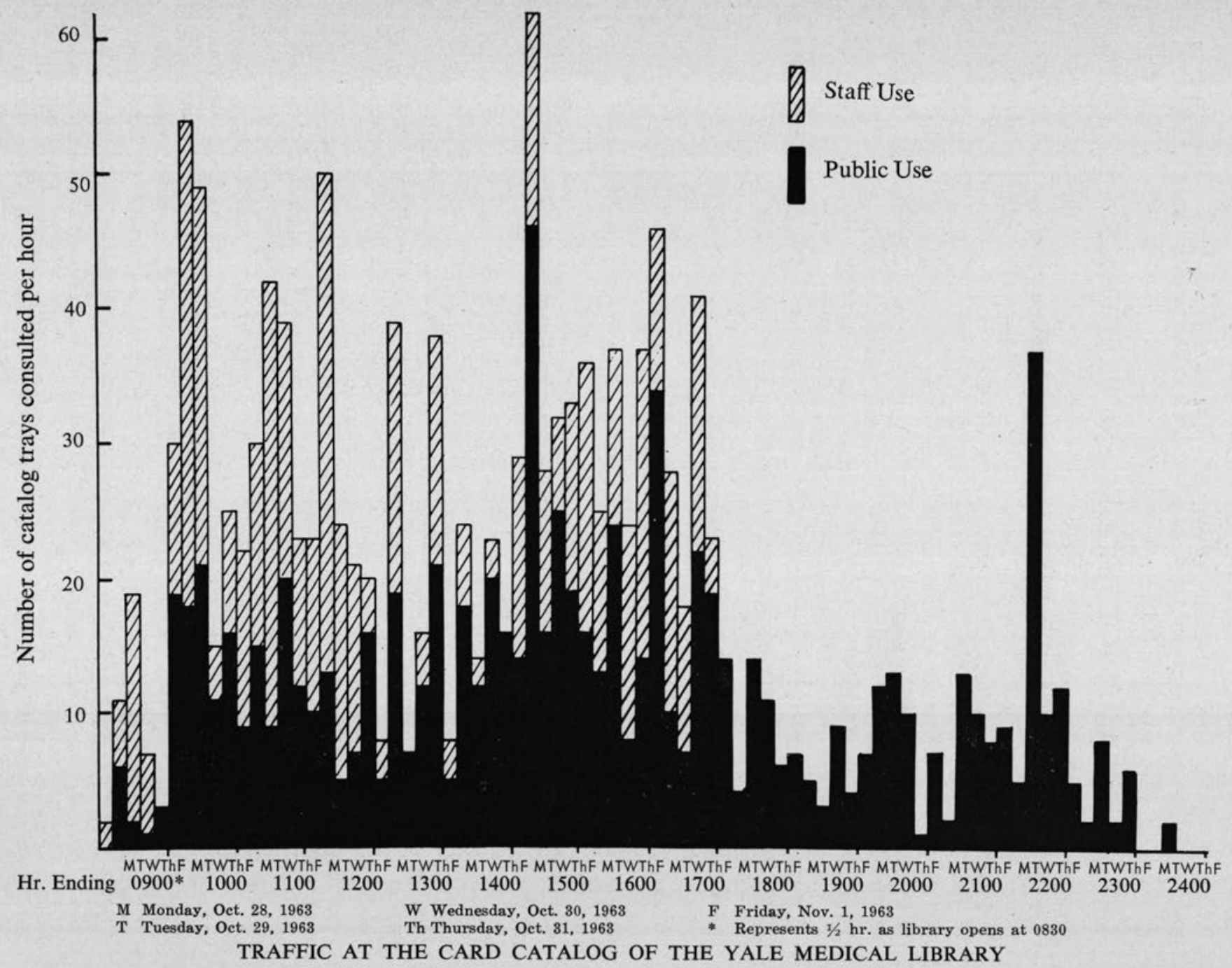


trays were consulted during all the hours of library opening ( 0830 to 2400 each day) of the observation period produced the information on traffic at the card catalog. This record reflects the "transactions" alone, disregarding information on users. Since the authors felt that a gross distinction could be made between the type of use made of the card catalog by the library staff of the technical service departments of cataloging and acquisitions (hereafter referred to as "staff") and that of the public plus other library personnel (hereafter referred to as "public"), the record makes this distinction. The only other distinction made in the record concerns the number of trays consulted by a particular user before leaving the card catalog, designated here as a "session."

Since the Yale medical library has a dictionary catalog, the observer could not record information concerning approach by subject, author, etc. Therefore, the authors designed an interview questionnaire to elicit these types of data. This form was purposely kept simple so that as much informality and "naturalness" could obtain in the interviews as possible. Interviews rarely required more than one or two minutes. Greater control in tabulating the results was possible since but a single interviewer filled out all the questionnaire forms. The interviewer set up a schedule of two-hour periods, during which he intended to interview all users of the card catalog. The recording of total traffic coincided with these two-hour periods so that the two parts of the study might serve as a check on each other. Each day the interviewer was on hand for six hours, staggered over various times during the library day so that every hour from 0830 to 2400 appeared on the schedule at least once. A few persons did escape being interviewed during three of the busier periods, but their number was small. The authors feel that the data thus obtained are statistically reliable since they agree closely with unpublished re- sults obtained during random interviewing periods which spanned a month.

\section{Results}

The accompanying figure depicts the traffic at the Yale medical library card catalog during the period of observation. First to be noted is that no clear pattern of card catalog use emerges, particularly in regard to staff. The least ambiguous result is that the hour 1400 through 1459 (recorded as 1500) comprises the peak use of the card catalog by the public.

Sessions at the card catalog consisted usually of one, two, or three drawers consulted, but the record was thirty (a member of the public checking forty-two separate periodical titles to see if the library possessed them). Staff members not infrequently consulted twenty or more trays before quitting the card catalog.

The table, analyzing the searches of public and staff in the card catalog by approach used, lists separately those searches in which subject approach was utilized and those in which subject approach was not utilized. It must be emphasized that nowhere do these figures reflect number of card catalog users (or interviews conducted), but rather the unit is the "search," here construed as all steps involved in locating a known item, or references to material on a subject. Thus, for example, a person who wished material on the subject of tuberculosis as it affects the spleen and who looked under "Tuberculosis" and "Spleen" was considered to have performed a single search.

The table indicates that 501 searches occurred during the thirty hours of interviewing and that these searches involved 601 card catalog entries, making approaches 120.0 per cent of searches. These 501 searches are divided nearly equally between 251 for the public representing 292 entries or 116.3 per cent of searches, and 250 for the staff representing 309 entries or 123.6 per cent of searches. Other figures to be commented 
SEARCHES OF PUBLIC AND STAFF IN THE CARD CATALOG OF THE YALE MEDICAL LIBRARY BY APPROACH USED

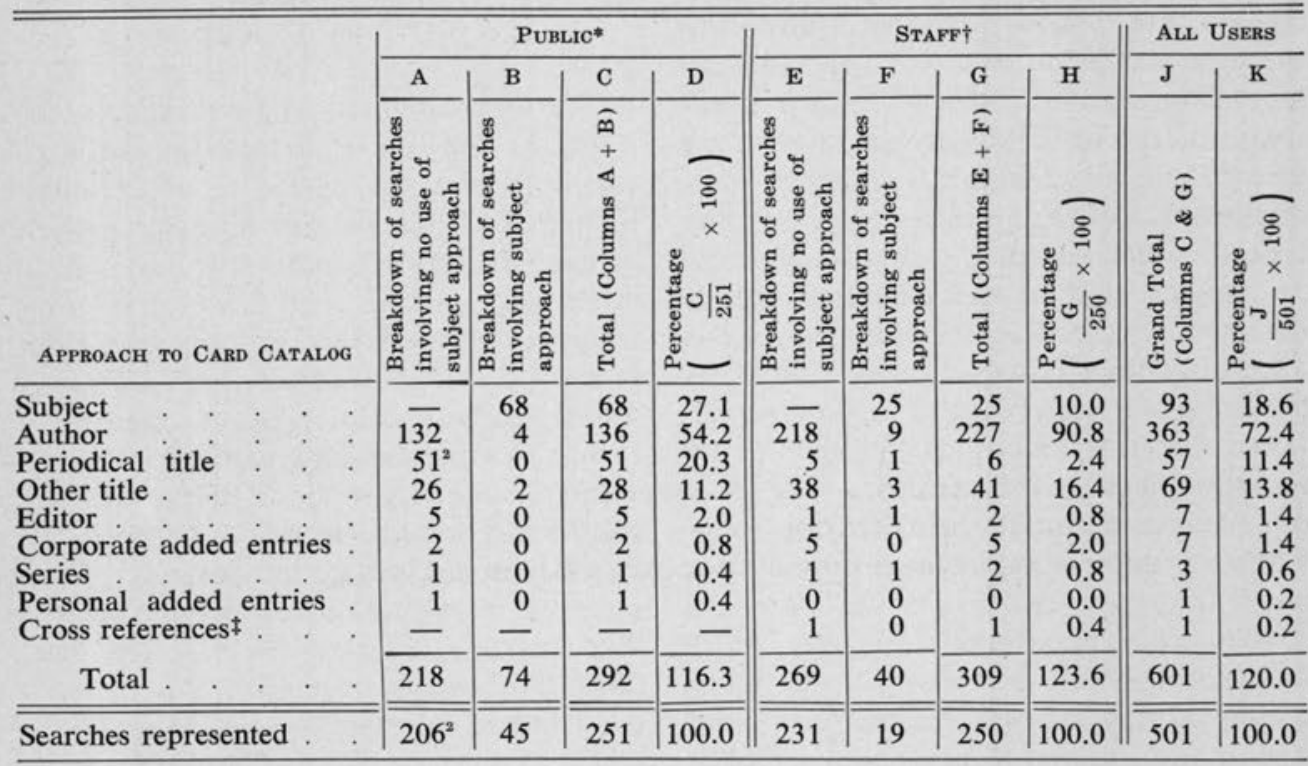

* "Public" is taken here as including all card catalog users except members of the library staff in the cata$\log$ department and acquisitions department only, who constitute "staff" in this table.

$\dagger$ This figure includes 42 titles, counted as 42 searches, because the individual was checking to see if the library possessed as many journals.

$\mp$ Included here as a special category for catalogers only where the card catalog was consulted specifically to check on a cross reference; use of cross references by others was regarded as approach by author, etc., as appropriate and is so listed.

on are the percentages in columns $\mathrm{D}, \mathrm{H}$, and $\mathrm{K}$. The public uses subject cards more than the staff-27.1 per cent for the public, 10.0 per cent for staff. Conversely, there is a higher use of the author approach by the staff- 90.8 per cent as compared to 54.2 per cent for the public. On the basis of figures in the table the percentage of subject use of the card catalog, calculated on the basis of the number of searches is 12.8 over-all or 17.9 if the public alone is considered. Regarding the subject searches, twenty-five of the public's forty-five, and five of the staff's nineteen, consisted of consultation of a single subject only; the largest number of subjects consulted in a single search was four, by a member of the public.

\section{Discussion}

Although, as has been mentioned above, no clear pattern emerges from the figure regarding times when the card catalog in the Yale medical library is most used (except for the 1400 through 1459 maximum as far as the public is concerned), the pattern for the public, together with the less clear pattern for staff can provide figures to help predict what size of load a computerized catalog should be prepared to handle. The high point seen at $2200 \mathrm{~W}$ does not give a picture of a typical Wednesday at that hour, for it includes the single thirty-tray session, the extreme for the observation period as noted above, but nonetheless points up the kind of peak which must be taken into account in deciding on capacity for computer operation.

Results of the interviewing constitute the table broken down by approach employed in searches. There was no attempt to separate main entries from others, but on the whole the approaches called "au- 
thor" and "periodical titles" represent main entries, while other approaches are added entries. The authors' strong impression is that users of the Yale medical library card catalog tend to seek their known item by means of the most direct or "obvious" approach.

What has been said above for the public applies to the staff as well, except that the staff makes particularly heavy use of the author approach, largely because of the extensive checking of items done by the acquisitions staff. The cataloging staff's use of the card catalog is predominantly to determine authority, for in the Yale medical library the public catalog is the authority for names and subject headings.

Additional information to come from the interviews must remain qualitative in nature because the limitedness of the subject use of the card catalog in this investigation does not permit statistically meaningful results. Nevertheless, the following indications are clear. First, the public seeks material in English almost exclusively, and at any rate preferentially. Second, publication dates of material sought by the subject approach parallel closely the findings of Kilgour ${ }^{6}$ regarding recorded use of books in the Yale medical library, indicating the heavy preference for locating as recent material as possible. Third, a considerable number of the public choose to locate a known item through the subject approach. Fourth, some individuals looked up a subject in the card catalog to learn the classification of the topic, or, in other words, as a quick guide to shelf location of material. And fifth, location of a particular form of material (e.g. periodicals of biochemistry, textbooks of embryology) constitutes a definable group of subject searches.

\section{CONCLUSION}

The peak load of catalog use between

\footnotetext{
- Frederick G. Kilgour, "Recorded Use of Books in the Yale Medical Library," American Documentation, XII (October 1961), 266-69.
}

1400 and 1500 hours can serve as a guide for predicting the amount of use that must be provided when a machine is available to do the searching.

An author catalog is required for the operation of a library, for the staff must be able to determine the library's holding before deciding to purchase or add a book to the collection. On the other hand, the subject catalog is designed primarily for public use. However, this study shows that the public makes relatively little use of the subject catalog at a time when public demand for more and more information is soaring. One conclusion to be drawn from these observations is that the traditional card catalog having an average of about 1.6 subject entries per book $^{7,8}$ does not furnish references adequate to meet new demands.

\section{SUMMARY}

An investigation of the use of subject cards in the catalog of the Yale medical library took place to aid in designing a catalog computerization project. Data gathered by continuous observation during a week of heavy use indicate that, in general, the peak traffic load at the card catalog occurs between 1400 and 1500 hours. On the basis of short interviews of card catalog users, 501 searches, which broke down almost equally between public-251, and staff-250, yielded sixtyfour or 12.8 per cent subject searches in all. If only the public is considered, there were forty-five or 17.9 per cent subject searches.

In a significant number of cases the purpose of the subject search is to locate a known item, obtain a quick guide to the shelves through the classification number, or to find a particular form of material (e.g., periodicals).

\footnotetext{
Peter M. Sprenkle, and Frederick G. Kilgour, "A Quantitative Study of Characters on Biomedical Catalogue Cards-A Preliminary Investigation," American Documentation, XIV (July 1963), 202-206.

${ }^{8}$ Henry J. Dubester, "Studies Related to Catalog Problems," The Library Quarterly, XXXIV (January 1964), 97-105.
} 